\title{
Deep left parietal lobe syndrome: conduction aphasia and other neurobehavioural disorders due to a small subcortical lesion
}

\author{
M PONCET, M HABIB, A ROBILLARD
}

From the Department of Neuropsychology, Neurological Clinic, University Hospital, Marseilles, France

SUMMARY A patient with sudden onset of conduction aphasia in the context of an ischaemic stroke is reported. Other neurological and neuropsychological findings included bilateral ideomotor apraxia, right hemisensory defect and paradoxical left ear extinction on a dichotic listening test. Lesion location, as inferred from magnetic resonance imaging, involved a restricted subcortical area in the left parietal lobe, near the lateral wall of the cerebral ventricle. The anatomical correlate for each of the clinical findings is discussed in the light of classical anatomo-clinical correlations. It is concluded that this tetrad constitutes a specific syndrome which may be easily recognised and ascribed to a single lesion in the deep white matter of the left parietal lobe.

In neurological practice, clinical attempts at predicting lesion localisation are usually derived from analysing neurobehavioural changes in correlation with their classical anatomical substrate. When several signs and symptoms are observed, an estimate about the lesion site may be obtained by combining their respective anatomical correlates. The purpose of this paper is to emphasise the localising value of the combination of four neurological and neuropsychological symptoms: conduction aphasia, bilateral ideomotor apraxia, hemisensory defect and paradoxical left ear extinction, a combination which specifically points to a restricted subcortical area of the left parietal lobe.

\section{Case report}

A 70 year old right-handed man, habitual smoker and neglected hypertensive, presented with a sudden onset of language difficulties and tingling in the right limbs. There were no headache, nausea or vomiting, nor was consciousness impaired at any moment. The patient was examined on admission as well as on numerous other occasions thereafter. He remained fully oriented and perfectly understood all spoken or written commands, but answered in a fluent paraphasic speech, mainly made up of phonemic paraphasias. Naming tasks brought evidence of consid-

Address for reprint requests: Dr $M$ Poncet, Département de Neuropsychologie, CHU Timone, F-13385 Marseille Cedex 5, France.

Received 2 May 1986. Accepted 26 June 1986 erable word-finding difficulties, and a tendency to approximate phonetically the designated image or object ("conduites d'approche" ${ }^{1}$ ). Repetition was marred by numerous phonemic paraphasias and neologisms (fig 1). Comprehension of written language was normal but reading aloud gave rise to numerous phonemic transformations and writing was made nearly impossible by the right hand sensory defect. This pattern of speech disturbance was consistent with the diagnosis of conduction aphasia. ${ }^{1}$ Visual fields were full, and cranial nerves appeared normal.

Reflexes were slightly brisker on the right, but there was no weakness. Plantar responses were flexor bilaterally. There was a right, proportional sensory deficit, more evident in the upper limb where pin sensation was inconsistently perceived, and always poorly localised; recognition of finger and toe movement was faulty, as were perception of vibration, graphesthesia, and stereognosia. On praxis testing, the patient would, both on command and imitation, produce bilaterally only poorly organised gestures, or perseverations. Frequently, body-part was assimilated to object. This pattern, notwithstanding the right sensory defect, was typical of bilateral ideomotor apraxia. However, gesture comprehension, as assessed by asking the patient to discriminate between apraxic and non-apraxic gestures, was found normal. The dichotic listening task was administered both in repetition and designation (multiple-choice) conditions: the patient showed a complete left ear extinction, none of the words sent to his left ear being repeated or designated.

The EEG was normal, and the CT scan, obtained on the 6th hospital day, only showed a questionable deep parietal hypodensity (fig 2). Magnetic resonance imaging (MRI) obtained 2 months after stroke, showed a well-circumscribed abnormal area in the depth of the parietal white matter, near 


MELODIC LINE
Intonational contour
PHRASE LENGTH
Longest occasional (1/10)
uninterrupted word runs
ARTICULATORY AGILITY
Facility at phonemic
and syllable level
GRAMMATICAL FORM
Variety of grammatical
construction (even if incomplete)
PARAPHASIA IN
RUNNING SPEECH
WORD FINDING
Informational content
in relation to fluency

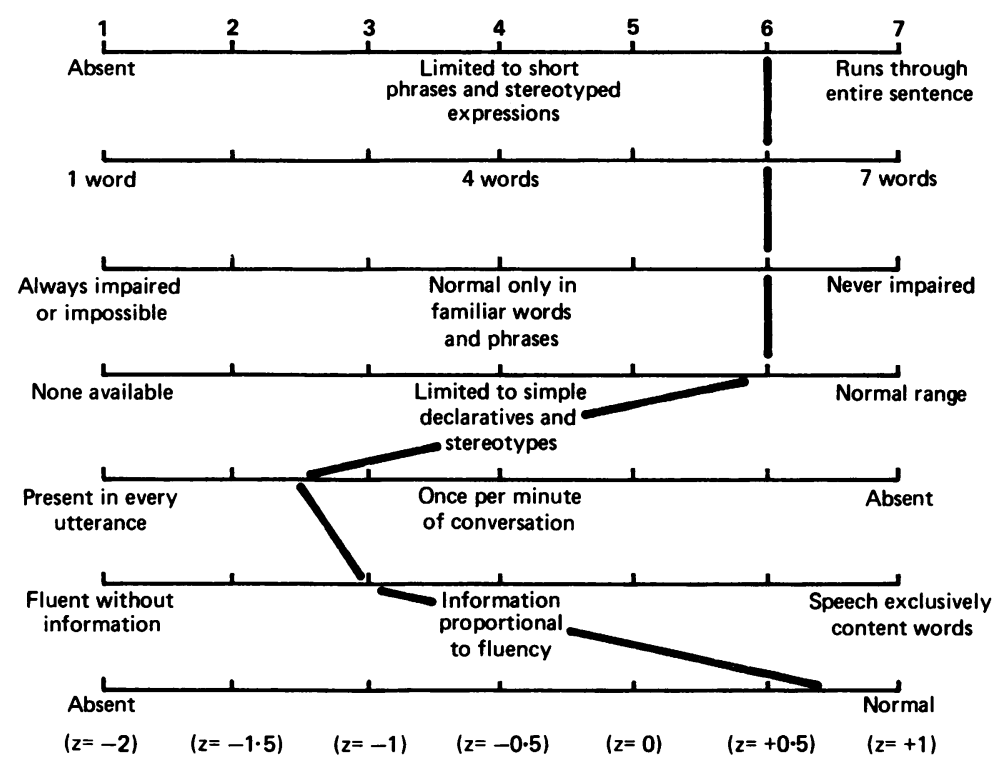

Fig 1 Boston Diagnostic Aphasia Examination rating scale profile of the patient's speech characteristics.

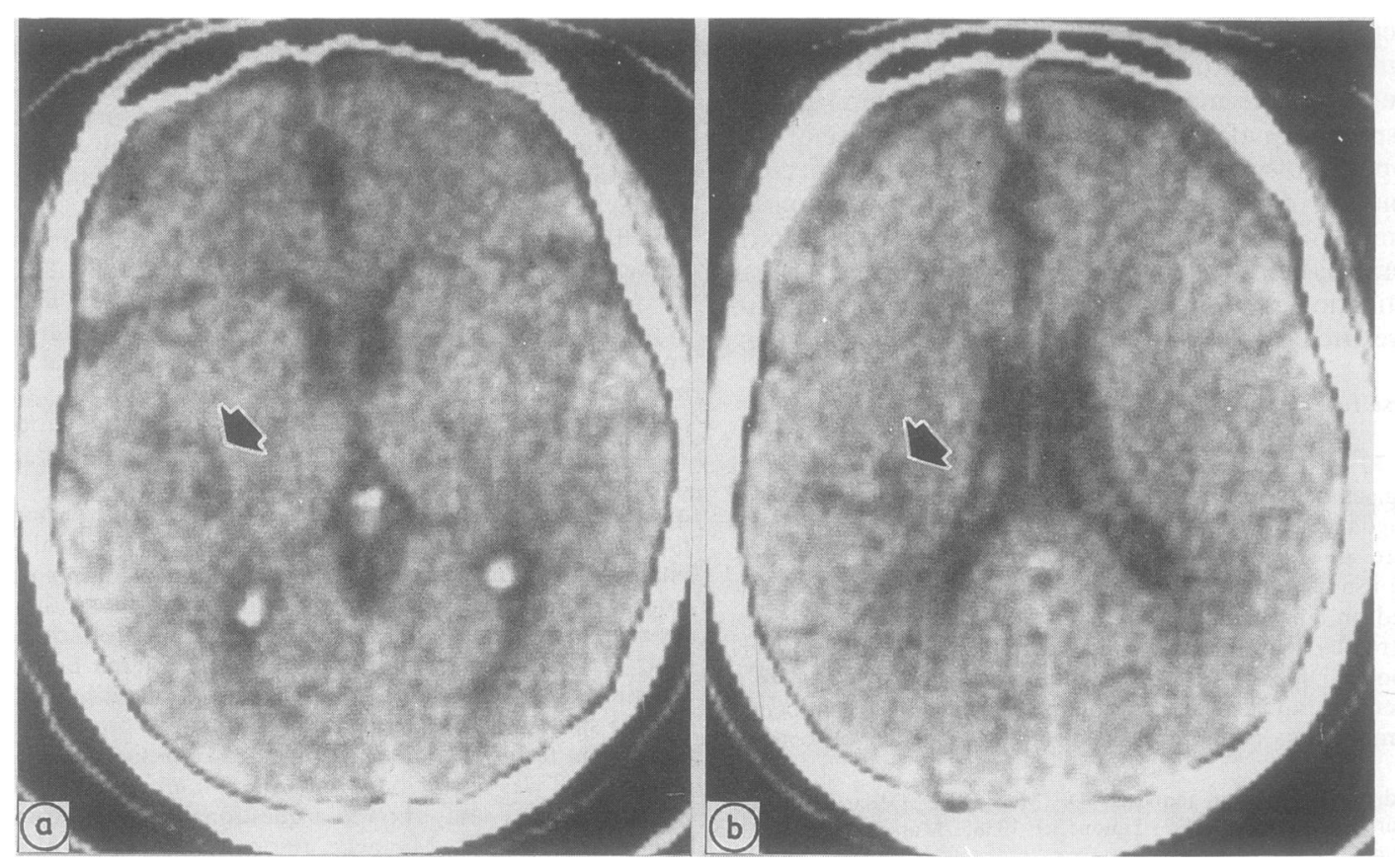

Fig 2 CT scan showing a small deep parietal white matter infarction (arrows). 


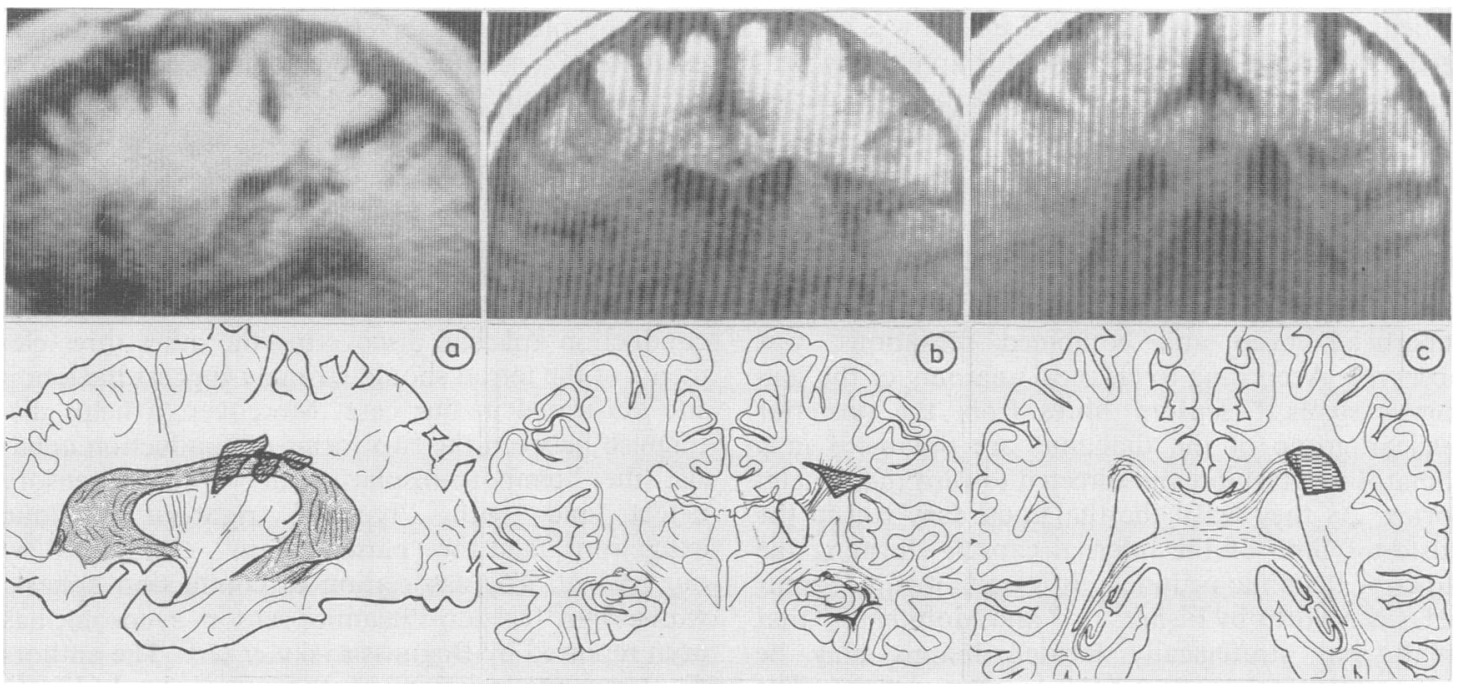

Fig 3 Magnetic resonance imaging obtained 2 months after stroke. (a) Saggital section, and schematic reconstruction showing the arcuate fasciculus (stippled area), probably damaged by the ischaemic infarct (hatched). (b) Coronal section at the level of the 3rd ventricle, and reconstruction illustrating the projected thalamo-cortical fibres and lesion site (hatched). (c) Coronal section at the level of the splenium showing the posterior extension of the infarct (hatched).

the insula, posterior and superior to the lenticular nucleus (fig 3), consistent with a small subcortical ischaemic infarct.

\section{Discussion}

The present observation deals with the coincident occurrence of conduction aphasia, bilateral ideomotor apraxia, right hemisensory defect, and paradoxical left ear extinction. In contrast with these dramatic neurological and neuropsychological changes, absence of any clouding of consciousness and nearly normal CT scan were suggestive of a very small lesion, which was confirmed by MRI. We will try to reconcile these apparently discrepant findings.

\section{(1) Conduction aphasia}

Historically, from the earliest monograph of Wernicke ${ }^{2}$ up to the modern disconnection theories of Geschwind, ${ }^{3}$ conduction aphasia has been mainly related to disruption of subcortical and/or cortical connecting systems between Wernicke's and Broca's areas, especially the arcuate fasciculus. It has been shown that conduction aphasia may be associated with two distinct anatomical patterns: ${ }^{45}$ (1) lesions involving the region of the left supra-marginal gyrus, deep enough to compromise the arcuate fasciculus. In this case, a strictly subcortical lesion seems to be sufficient to produce the syndrome (Benson et al: ${ }^{4}$ case 3). (2) damage to the insular and auditory cortices and underlying white matter, probably compromising another connecting pathway running through or underneath the insular cortex. ${ }^{6}$ Despite some con- tradictions, ${ }^{7-9}$ it is generally admitted that a disconnection theory is able to account, at least schematically, for most cases of conduction aphasia, ${ }^{10}$ whether of the first or the second type. Our case probably belongs to the first type, as it clearly appears from MRI and accompanying anatomical reconstructions (fig 3a) that the small, subcortical lesion involves the arcuate fasciculus during its course under the parietal cortex, where it arches forward in the direction of the frontal premotor cortex. ${ }^{11}$

\section{(2) Ideomotor apraxia}

Classically, bilateral apraxia may result from lesions involving either the lower parietal region (the angular and supramarginal gyri) or more anterior regions of the left hemisphere. As for language processing, the arcuate fasciculus is thought, here again, to play a central role in motor behaviour. ${ }^{12-14}$ Benson et al ${ }^{4}$ came to isolate within conduction aphasics a group of patients showing bilateral apraxia. These patients always had supra-sylvian lesions. To explain this association, these authors proposed that the arcuate fasciculus received, on its way towards the frontal cortex, input from the parietal lobe and especially from the supramarginal cortex. Thus, bilateral ideomotor apraxia may result from lesions involving (1) the parietal cortex; (2) white matter subjacent to it; or (3) the arcuate fasciculus. According to Heilman et $a l,{ }^{15}$ among apraxic patients, those with good gesture comprehension will prove on CT to have lesions sparing the parietal cortex. This was the case of our 
patient whose strictly subcortical infarct was so situated as to cause bilateral ideomotor apraxia by producing a disconnection between the parietal cortex and the arcuate fasciculus, and/or by compromising the arcuate fasciculus itself (fig 3a).

\section{(3) Hemisensory defect}

Along with the two above disorders, a dense unilateral right sensory deficit, equally involving superficial, deep and combined sensations, was observed. According to classical anatomy of the sensory systems, ${ }^{16}$ sensory fibres from the posterior nuclear group of the thalamus are organised in a somatotopic fashion and directed toward the parietal cortex. As they leave the thalamus, they run in the posterior limb of the internal capsule, forming the superior thalamic peduncle. It is quite readily admitted, since works by Fisher ${ }^{17-19}$ and Mohr et al ${ }^{20}$ that small, but strategically located lesions may be responsible for proportional sensory deficits. The location of the lesion depicted on fig $3 \mathrm{~b}$, lying just above the posterior nuclear group of the thalamus, and probably damaging the thalamo-parietal fibres provides a satisfactory explanation for the sensory symptoms.

\section{(4) Paradoxical left ear extinction}

In dichotic conditions, some hemispheric lesions are known possibly to cause a phenomenon of extinction of either ear. In such cases, according to classical demonstrations, ${ }^{2122}$ the extinction usually concerns the contralaterally received message. In a number of right-handed patients with left hemisphere lesions, the reverse pattern is realised (that is, a "paradoxical" left ear extinction): in such cases, it is assumed that the lesion has compromised callosal fibres conveying verbal information from the right hemisphere to the intact left auditory cortex. The exact location of this callosal pathway, connecting the right and left auditory areas is still not defined. In the Rhesus monkey, ${ }^{23}$ such inter-temporal connections have been demonstrated to course at the junction between the body and the splenium of the callosum, just rostral to the visual inter-occipital fibres. The human pattern of callosal connections is probably very similar. ${ }^{24}$ Damasio and Damasio ${ }^{25}$ proposed, through correlations based on CT of several patients with paradoxical extinction, that this inter-temporal connecting tract is situated deep in the parietal or parieto-occipital white matter, near the lateral wall of the lateral ventricle, outside the optic radiations.

Coronal views of MRI (fig 3c) in our patient show that the situation of the lesion is quite consistent with this explanation.

In our view, several points of interest may be drawn from the present case report. First, it provides an example of a striking discrepancy between a discrete lesion, without clinical evidence of any mass effect and hardly detectable on CT scan, and massive neurobehavioural disorders. Such a discrepancy represents, per se, a good argument for predicting a subcortical lesion.

It also identifies a neurological entity which could be acknowledged as a new syndrome: in the context of conduction aphasia, discovering the other three elements of the tetrad should strongly suggest the lesion site illustrated in our case. Moreover, it helps distinguish between the two forms of conduction aphasia: the "temporo-insular form" without sensory defect and with "typical" right-ear dichotic extinction ${ }^{26}$ and the "parietal form", exemplified by our patient. The association of conduction aphasia with a right "pseudo-thalamic" sensory syndrome has been reported by Bogousslavsky et al. ${ }^{27}$ The authors discussed the relation of their case to Luria's ${ }^{28}$ afferent motor aphasia and the participation of a deafferentation mechanism. It is in fact conceivable that, in some conduction aphasics, both mechanisms (deafferentation and temporo-frontal disconnection) may jointly contribute to the speech disturbance pattern.

As already mentioned, the association of conduction aphasia with ideomotor apraxia has been pointed $\triangle$ out by Benson et $\mathrm{al}^{4}$ as suggestive of a parietal lesion. Yet one cannot be sure clinically that the parietal cortex is spared, since a similar pattern may result from lesions involving the supramarginal gyrus. Such lesions, however, would not produce the other two elements of the syndrome unless they extend deep enough to damage the relevant subcortical pathways: one may contend that, in such cases, the deepest part of the lesion is sufficient to cause the full syndrome.

Finally, one may speculate about the aetiology of the infarct responsible for this syndrome in our patient. Rather than a true lacune according to Fisher's ${ }^{19}$ definition or occlusion of a single vessel, ${ }^{27}$ it seems to us that the location is more compatible with a watershed infarction occurring in a zone of high susceptibility to decreased blood flow, supplied by the terminal perforating branches of the distal middle cerebral artery. If this is actually the case, then the syndrome described in this paper should, when systematically searched for, be diagnosed much more often.

\section{References}

1 Goodglass H, Kaplan E. The Assessment of Aphasia and Related Disorders. Philadelphia: Lea \& Febiger, 1972.

2 Wernicke C. Der Aphasische Symptomenkomplex. Breslau: Cohn \& Weigert, 1874.

3 Geschwind N. Disconnexion syndromes in animal and 
man. Brain 1965;88:237-94; 585-644.

4 Benson DF, Sheremata WA, Bouchard R, Segarra JM, Proce D, Geschwind N. Conduction aphasia: a clinicopathological study. Arch Neurol 1973;28:339-46.

5 Damasio H, Damasio AR. The anatomical basis of conduction aphasia. Brain 1980;103:337-50.

6 Damasio H, Damasio AR. Localization of lesion in conduction aphasia. In: Kertesz A, ed. Localization in Neuropsychology. New York: Academic Press, 1983.

7 Levine DN, Calviano R. Conduction aphasia. In: Kirshner HS, Freemon FR, eds. The Neurology of Aphasia: Neurolinguistics. Amsterdam: Swets \& Zeitlinger, 1982.

8 Luria AR, Hutton JT. A modern assessment of the basic forms of aphasia. Brain Lang 1977;4:129-51.

9 Warrington EK, Shallice T. The selective impairment of auditory verbal short-term memory. Brain 1969;92: 885-96.

10 Mendez MF, Benson DF. Atypical conduction aphasia. A disconnection syndrome. Arch Neurol 1985;42: 886-91.

11 Dejerine JJ. Anatomie des Centres Nerveux. Paris: Rueff, 1908.

12 Geschwind N. The apraxias: Neural mechanisms of disorders of learned movements. American Scientist 1975;63:188-95.

13 Heilman KM, Rothi L, Kertesz A. Apraxia. In: Kertesz A, ed. Localization in Neuropsychology. New York: Academic Press, 1983.

14 Geschwind N, Damasio AR. Apraxia. In: Frederiks JAM, ed. Handbook of Clinical Neurology. Vol 1(45), Clinical Neuropsychology. Amsterdam: Elsevier, 1985.

15 Heilman KM, Rothi LJ, Valenstein E. Two forms of ideomotor apraxia. Neurology 1982;32:342-6.

16 Carpenter MB. Human Neuroanatomy. 7th ed. Bal- timore: William \& Wilkins, 1976.

17 Fisher CM. Pure sensory stroke involving face, arm, and leg. Neurology 1965;15:76-80.

18 Fisher CM. Thalamic pure sensory stroke: a pathologic study. Neurology 1978;28:1141-4.

19 Fisher CM. Lacunes: Small deep cerebral infarcts. Neurology 1965;15:774-84.

20 Mohr JP, Kose CS, Meckler MD, Fisher CM. Sensorymotor stroke due to thalamocapsular ischaemia. Arch Neurol 1977;34:739-41.

21 Sparks KM, Goodglass H, Nickel B. Ipsilateral versus contralateral extinction in dichotic listening resulting from hemispheric lesions. Cortex 1970;6:249-60.

22 Michel F, Péronnet F. Extinction gauche au test dichotique: lésion hémisphérique ou lésion commisurale? In: Michel F, Schott B, eds. Les Syndromes de Déconnexion Calleuse chez l'Homme. Lyon, 1975.

23 Pandya DN, Hallet M, Murkherjee SK. Intra and interhemispheric connection of the neocortical auditory system in the Rhesus monkey. Brain Res 1969;14: 49-65.

24 De Lacoste MC, Kirkpatrick JB, Ross ED. Topography of the human corpus callosum. $J$ Neuropathol Exp Neurol 1985;44,6:578-91.

25 Damasio H, Damasio AR. "Paradoxic" ear extinction in dichotic listening: possible anatomic significance. $\mathrm{Neu}$ rology 1979;29:644-53.

26 Damasio H, Damasio AR. Dichotic listening pattern in conduction aphasia. Brain Lang 1980;10:261-6.

27 Bogousslavsky J, Assal G, Regli F. Aphasie afférente motrice et hémisyndrome sensitif droit. Le syndrome de l'artère pariétale antérieure gauche. Rev Neurol (Paris) 1982;138:649-55.

28 Luria AR. Basic Problems in Neurolinguistics. The Hague-Paris: Mouton, 1976. 